\title{
Case control study of thermal environment preceding haemorrhagic shock encephalopathy syndrome
}

\author{
C J Bacon, S A Bell, J M Gaventa, D C Greenwood
}

\begin{abstract}
The purpose of the study was to investigate whether the thermal environment in which babies slept before developing haemorrhagic shock encephalopathy syndrome (HSES) differed from that of other babies. Data were collected by standardised interview from parents of 31 babies who had had HSES before the age of 7 months and compared with equivalent data for 124 control babies, with matching for outside temperature on the relevant night and for age. Multivariate analysis showed a strong association between HSES and covering of the baby's head by bedding, the odds ratio being 30.7 (95\% confidence interval, 2.5 to 384 ). There were weaker associations with other aspects of the thermal environment. This suggests a link between HSES and some cases of cot death, supports the suggestion that HSES may be caused by overheating, and reinforces advice that babies should be placed to sleep in such a way that they are less likely to become totally covered. (Arch Dis Child 1999;81:155-158)
\end{abstract}

Keywords: haemorrhagic shock encephalopathy syndrome; head covering; sudden infant death syndrome; overheating; hyperthermia

Friarage Hospital, Northallerton, North Yorkshire DL6 1JG, UK C J Bacon

Department of Child Health, Royal Victoria Infirmary, Newcastle upon Tyne NE1 4LP, UK

S A Bell

Institute of Child

Health, London WC1N 1EH, UK

J M Gaventa

Medical Statistics, Nuffield Institute for Health, Leeds LS2 9PL, UK

D C Greenwood

Correspondence to: Dr Bacon.

Accepted 26 March 1999 that it might be a form of heatstroke, which has the same clinical and pathological features. ${ }^{4-7}$ Hitherto, few reports of HSES have docu- mented obvious exposure to excessive heat. However, it is possible that, in certain circumstances, the thermal environment chosen by a mother for her baby (with the best intentions) might become injurious - for example, if the room becomes too hot or the head accidentally becomes covered by the bedding. It is also possible that the fever of an infection might contribute to overheating, and that there might be individual differences in response to thermal stress.

In our study we aimed to determine whether there are significant differences between the thermal environment of babies who incur HSES and that of other babies in the general population.

\section{Methods}

The second phase of national surveillance, which took place between 1985 and 1988 and included a review of the case notes, identified 52 cases that satisfied the criteria for HSES. ${ }^{3}$ It was intended that all the families should be interviewed, excluding four whose children were over 6 months old at the time of their illness and two that lived in Northern Ireland. However, of the 46 eligible families, four could not be traced, eight did not wish to participate, and for three others the family doctor or the paediatrician withheld consent. The remaining 31 families were visited by one of two research interviewers who collected data on a standard questionnaire about all aspects of the baby's thermal environment on the night that the illness struck, plus basic personal and social details. The outside temperature measured at the nearest recording station at midnight on the night in question was obtained from the Meteorological Office. The mean interval between illness and interview was 23 weeks (range, 8-39). So far as possible details given by parents were checked against contemporary hospital records.

At the same time as this study of HSES was in progress a survey was being conducted in London and Newcastle to delineate how babies aged 6 months or less in the general population were kept warm. The method for this survey has been described in a previous report. ${ }^{8}$ In brief, a total of 1400 mothers were selected by random sampling and interviewed at all times of year by the same research interviewers using the same standard questionnaire as for the HSES study. Data collected included details of the baby's thermal environment on the previous night.

For each case of HSES, four controls were selected from the population survey who 
Table 1 Characteristics of cases and controls and details of their thermal environment

\begin{tabular}{|c|c|c|}
\hline & $\begin{array}{l}\text { HSES cases } \\
(n=31)\end{array}$ & $\begin{array}{l}\text { Controls } \\
(n=124)\end{array}$ \\
\hline $\begin{array}{l}\text { Age in weeks (mean (SD)) } \\
\text { Boys } \\
\text { Social class } \\
\text { I/II } \\
\text { IIINM/IIIM } \\
\text { IV/V } \\
\text { Outside temperature in }{ }^{\circ} \mathrm{C}(\text { mean }(\mathrm{SD}))\end{array}$ & $\begin{array}{l}15.4(6.0) \\
18(58) \\
5(17) \\
11(38) \\
13(45) \\
9.2(4.1)\end{array}$ & $\begin{array}{l}49(41) \\
45(38) \\
26(22) \\
9.2(4.1)\end{array}$ \\
\hline $\begin{array}{l}\text { Duration of room heating } \\
\text { None } \\
\text { Until baby was put down } \\
\text { Part of night } \\
\text { All of night }\end{array}$ & $\begin{array}{l}11(35) \\
3(10) \\
7(23) \\
10(32)\end{array}$ & $\begin{array}{l}29(23) \\
47(38) \\
32(26) \\
16(13)\end{array}$ \\
\hline $\begin{array}{l}\text { Duration of heating baby's cot } \\
\text { None } \\
\text { Until baby was put down } \\
\text { Part of night } \\
\text { All of night }\end{array}$ & $\begin{array}{l}29(94) \\
2(6) \\
0(0) \\
0(0)\end{array}$ & $\begin{array}{l}114(92) \\
8(6) \\
1(1) \\
1(1)\end{array}$ \\
\hline $\begin{array}{l}\text { Main type of bedding } \\
\text { No bedding } \\
\text { Blankets } \\
\text { Duvet (with or without blankets) } \\
\text { Baby nest or sleeping bag } \\
\text { Swaddled } \\
\text { Total insulation in togs (mean (SD)) }\end{array}$ & $\begin{array}{l}1(3) \\
7(23) \\
22(71) \\
1(3) \\
9(29) \\
9.8(3.2)\end{array}$ & $\begin{array}{l}1(1) \\
49(40) \\
73(59) \\
1(1) \\
21(17) \\
8.1(3.5)\end{array}$ \\
\hline $\begin{array}{l}\text { Degree of covering by bedding } \\
\text { Completely uncovered } \\
\text { Head uncovered, body partly covered } \\
\text { Head uncovered, body wholly covered } \\
\text { Head partly or wholly covered, body covered } \\
\text { Hat worn }\end{array}$ & $\begin{array}{l}2(6) \\
6(19) \\
14(45) \\
9(29) \\
0(0)\end{array}$ & $\begin{array}{l}17(14) \\
54(44) \\
41(33) \\
11(9) \\
2(2)\end{array}$ \\
\hline $\begin{array}{l}\text { Amount of sweating while asleep } \\
\text { None } \\
\text { Slight } \\
\text { Moderate } \\
\text { Profuse }\end{array}$ & $\begin{array}{l}20(65) \\
2(6) \\
5(16) \\
4(13)\end{array}$ & $\begin{array}{l}98(79) \\
16(13) \\
7(6) \\
3(2)\end{array}$ \\
\hline $\begin{array}{l}\text { Parents' estimate of baby's temperature while asleep } \\
\text { Below normal } \\
\text { Normal } \\
\text { Slightly raised } \\
\text { High } \\
\text { Signs of infection in baby in previous } 24 \text { hours } \\
\text { Infection in other members of household in previous five days } \\
\text { Baby sleeping in parents' bed }\end{array}$ & $\begin{array}{l}1(4) \\
23(85) \\
2(7) \\
1(4) \\
12(39) \\
12(39) \\
1(3)\end{array}$ & $\begin{array}{l}1(1) \\
107(86) \\
16(13) \\
0(0) \\
36(29) \\
56(45) \\
2(2)\end{array}$ \\
\hline
\end{tabular}

Values are $\mathrm{n}(\%)$ unless otherwise stated.

NM, non-manual; $M$, manual.

matched the index case most closely first for outside temperature and then for age. Where more than four equivalent controls were available selection was made by use of random tables. The four cases of HSES in babies aged over 6 months were excluded because there were no controls of similar age. Total insulation was calculated from the insulation provided by each item of clothing and bedding and the pro-

Table 2 Unadjusted odds ratios from single variable analyses for factors that showed significant associations at the $10 \%$ level

\begin{tabular}{llll}
\hline & Odds ratio & $95 \%$ CI & p Value \\
\hline Degree of covering by bedding & & & \\
Completely uncovered & 1.00 & - & \\
Head uncovered, body partly covered & 0.85 & 0.15 to 4.83 & \\
Head uncovered, body wholly covered & 2.49 & 0.41 to 15.1 & \multirow{2}{*}{0.001} \\
Head partly or wholly covered, body covered & 18.3 & 2.06 to 162 & \\
Duration of room heating & & & \\
None & 1.00 & - & \\
Until baby was put down & 0.38 & 0.09 to 1.60 & \\
Part of night & 1.21 & 0.35 to 4.19 & \\
All of night & 3.62 & 0.92 to 14.2 & \\
Social class & & & \\
I/II & 1.00 & - & \\
IIINM/IIIM & 1.91 & 0.55 to 6.64 & \\
IV/V & 4.39 & 1.23 to 15.69 & 0.053 \\
Total insulation (togs) & & & \\
$<5$ & 1.00 & - & \\
$5-9.9$ & 6.17 & 0.79 to 48.1 & \\
$>10$ & 4.93 & 0.53 to 45.9 & 0.085 \\
\hline
\end{tabular}

CI, confidence interval; NM, non-manual; $M$, manual. portion of the baby's surface that it covered (EE Clulow, personal communication, 1986).

STATISTICAL ANALYSES

The primary analyses were carried out using conditional logistic regression. Variables examined for possible association with HSES were sex, social class, duration of room heating, heating of the baby's cot, main type of bedding, swaddling, total insulation, degree of covering by bedding when found in the morning, wearing a hat, amount of sweating while asleep, parents' estimate of baby's temperature while asleep, signs of infection in the previous 24 hours, infection in other members of the household in the previous five days, and sharing the parents' bed. Two potential confounders, outside temperature and age, were subject to individual matching. Initially, a separate single variable model was produced for each factor. A stepwise procedure was then used to select variables for inclusion in a single model that contained all independent predictors of HSES, after adjustment for other important variables and exclusion of those that did not remain significant at the 5\% level. Six index cases for which data were incomplete, together with their controls, were excluded from this multiple conditional logistic regression model. To assess robustness of findings, analyses were repeated with all cases and controls included, ignoring the matching and using unconditional logistic regression. Analyses were carried out with SPSS version $6.1^{9}$ and GLIM version $4 .^{10}$

\section{Results}

All controls were matched for outside temperature within $1^{\circ} \mathrm{C}$ of their corresponding index case. Seventy seven (62\%) controls were matched within 1 week of age, $99(80 \%)$ within 2 weeks, and all within 4 weeks of their index case.

Table 1 shows the characteristics of the 31 cases of HSES and the 124 controls and details of their thermal environment.

Analysis by separate single variable conditional regression yielded associations that were significant at the $10 \%$ level in respect of four variables: social class, total insulation, duration of room heating, and degree of covering by bedding (table 2).

When analysed by multiple conditional logistic regression, adjusted odds ratios remained significant in respect of social class, duration of heating, and degree of covering (table 3), but not for total insulation. Analysis by unconditional logistic regression produced similar although slightly more conservative odds ratios.

The number of cases in our study is too small to allow formal investigation of combinations of factors. However, there was a suggestion of synergy between high insulation and infection, and between high insulation and room heating, the association between these combinations and HSES being stronger than it was for high insulation alone. No synergy was apparent between infection and room heating. 
Table 3 Adjusted odds ratios for variables included in the multiple conditional logistic regression model

\begin{tabular}{|c|c|c|c|}
\hline & Odds ratio & $95 \% C I$ & $p$ Value \\
\hline \multicolumn{4}{|l|}{ Degree of covering by bedding } \\
\hline Completely uncovered & 1.00 & - & \\
\hline Head uncovered, body partly covered & 0.60 & 0.05 to 6.86 & \\
\hline Head uncovered, body wholly covered & 2.77 & 0.33 to 23.3 & \\
\hline Head partly or wholly covered, body covered & 30.66 & 2.45 to 384 & $<0.001$ \\
\hline \multicolumn{4}{|l|}{ Social class } \\
\hline I/II & 1.00 & - $\quad$ & \\
\hline IIINM/IIIM & 2.14 & 0.41 to 11.1 & \\
\hline IV/V & 12.85 & 1.62 to 102 & 0.010 \\
\hline \multicolumn{4}{|l|}{ Duration of room heating } \\
\hline None & 1.00 & - & \\
\hline Until baby was put down & 0.24 & 0.04 to 1.61 & \\
\hline Part of night & 0.87 & 0.19 to 4.01 & \\
\hline All of night & 5.24 & 0.66 to 41.4 & 0.013 \\
\hline
\end{tabular}

CI, confidence interval; NM, non-manual; $M$, manual.

\section{Discussion}

Our findings suggest that the thermal environment of babies who incur HSES may differ from that of most other babies, particularly with regard to covering of the head by bedding. However, we acknowledge that there are limitations to our study that need consideration.

The response rate for index cases, with a third of intended subjects not included, was disappointing. However, the epidemiological and clinical profile of non-responders, as ascertained from the case notes, was very similar to that of responders, so we are confident that our sample was representative. Furthermore, for such an uncommon illness a series of 31 verified cases is quite substantial.

The long interval between illness and interview was also a disadvantage and increases the potential for recall bias. The delay arose from the lag inherent in the reporting system, and from subsequent difficulties in tracking down the families and obtaining permission to visit from all those concerned. However, experience has shown that parents recall clearly the circumstances surrounding the death or serious illness of a child for a long time afterwards, and checking against contemporary hospital records revealed few discrepancies. We think it unlikely that recall bias influenced our results greatly. Our study was conducted before overheating was publicised as a possible risk factor for cot death, so that recall bias about the thermal environment, arising from differential reporting between cases and controls, would not be expected particularly. In addition, recall bias would be expected to show greatest effect in the most subjective area, which involved an estimate of the baby's temperature while asleep but the response to this question from mothers of cases and controls was very similar.

The finding of an association between HSES and lower social class might partly be explained by a skewed response rate among controls, among whom higher social class families were over-represented. ${ }^{8}$ The same social imbalance may also have contributed to the finding of a generally warmer thermal environment among cases of HSES, because it has been shown that babies from lower social class families are generally kept warmer. ${ }^{811}$

However, in the multiple analysis, after adjustment for social class, two important components of the thermal environment remained significant; namely, heating of the baby's room for the whole night and covering of the head by the bedding, the latter giving a particularly high odds ratio. Index babies also tended to have more insulation, although this did not remain significant in the multiple analysis. About half of all index and control babies had signs of illness or recent contact with infection, which again illustrates the high prevalence of minor infection among families in the community. No data were collected about smoking or about sleeping position.

Covering of the head by bedding is also known to be a major risk factor for cot death. ${ }^{12}$ Suggested mechanisms include asphyxia ${ }^{13}$ or overheating $^{14}$ : our demonstration that covering of the head may lead to an illness identical to heatstroke supports the latter. The combination of infection and heavy wrapping in our study tending to an association with HSES has also been shown to bring an increased risk of cot death. ${ }^{15}$ In addition, a link between some cases of cot death and HSES is suggested by their similar age range and male predominance, and by the simultaneous occurrence of cot death and HSES in twins. ${ }^{16}$

We believe that our findings support the view that HSES, at least in many cases, is a form of heatstroke. Sleeping babies subjected to a rise in ambient temperature or insulation maintain thermal homeostasis by losing excess heat from their heads. ${ }^{17}$ It has been shown that piglets placed in a warm environment become dangerously overheated if their heads are covered. ${ }^{18} 19$ Theoretical calculations suggest that this may happen in human babies. ${ }^{14}$ Therefore, it seems feasible that a sleeping baby can cope with ambient temperatures and insulation that are in excess of the ideal but within the range of normal practice so long as the head remains uncovered, but once this route for dissipating surplus heat is lost may be subjected to an intolerable thermal load. There was no history of gross overwrapping in the cases of HSES reported in the first phase of the national surveillance scheme from 1982 to $1984 .{ }^{2}$ However, the seven most typical cases were all covered by duvets, which confer high insulation, and soaked in sweat when found, which denotes a strenuous attempt to lose heat. It is not recorded whether their heads had become covered by their bedding, and it is possible that this vital question was not asked.

If overheating is a cause both for some cases of cot death and HSES, then it would appear to act in two modes, either sudden death or the evolution of heatstroke, which itself may also often be fatal. However, it should be noted that not all the cases of HSES in our study had factors conducive to overheating, while some of the controls had such factors but remained well. This supports the notion that there may be individual differences in response to thermal stress. It also raises the possibility that HSES, as currently defined, may not be a homogeneous entity.

The demonstration that covering of a baby's head by bedding brings a risk not only of cot death but also of HSES reinforces the advice 
that babies should be put down to sleep in a manner that minimises this possibility. This advice is well conveyed in the leaflet issued jointly by the Foundation for the Study of Infant Deaths and the Department of Health recommending that the baby should be placed with the feet touching the bottom end of the cot so that slipping down under the bedclothes is less likely. ${ }^{20}$ It is possible that this and other recent publicity about overheating in relation to cot death may have led to a reduction in HSES as well, making an uncommon condition even rarer and further studies more difficult.

We are grateful to the Foundation for the Study of Infant Deaths, who funded this study, and to the British Paediatric Surveillance Unit, whose cooperation enabled us to collect the data. We also thank the many mothers who took part, especially those whose babies had HSES.

1 Levin M, Hjelm M, Kay JD, et al. Haemorrhagic shock and encephalopathy: a new syndrome with a high mortality in young children. Lancet 1983;ii:64-7.

2 Joint British Paediatric Association and Communicable Diseases Surveillance Centre surveillance scheme for haemorrhagic shock encephalopathy syndrome: surveillance report for 1982-4. BMF 1985;290:1578-9.

3 Bacon CJ, Hall SM. Haemorrhagic shock encephalopathy syndrome in the British Isles. Arch Dis Child 1992;67:985syn

4 Bacon CJ. Heatstroke and haemorrhagic shock and encephalopathy. Lancet 1983;ii:918.

5 Beaufils F, Aujard Y. Haemorrhagic shock and encephalopathy syndrome. Lancet 1983;ii:1086.

6 Corrigan JJ. The " $H$ " in hemorrhagic shock and encephalopathy syndrome should be "hyperpyrexia" [editorial]. Am f Dis Child 1990;144:1077.
7 Stanton AN. Haemorrhagic shock and encephalopathy. Lancet 1985;ii:1019-20.

8 Bacon CJ, Bell SA, Clulow EE, Beattie AB. How mothers keep their babies warm. Arch Dis Child 1991;66:627-32.

9 SPSS Inc. SPSS for Windows: advanced statistics user's guide, release 6.1. Chicago: SPSS Inc, 1996.

10 Francis B, Green M, Payne C, eds. The GLIM system: generalised linear interactive modelling. Oxford: Oxford University Press, 1993.

11 Fleming PJ, Gilbert R, Azaz Y, et al. Interaction between bedding and sleeping position in the sudden infant death syndrome: a population based case-control study. BMF 1990;301:85-9.

12 Fleming PJ, Blair PS, Bacon CJ, et al. Environment of infants during sleep and risk of sudden infant death syndrome: results of 1993-5 case-control study for confidential inquiry into stillbirths and deaths in infancy. BMF 1996;313:191-5.

13 Campbell AJ, Bolton DPG, Williams SM, Taylor BJ. A potential danger of bedclothes covering the face. Acta Paepotential danger of bedcloth
diatr Scand 1996;85:281-4.

14 Jardine DS. A mathematical model of life-threatening hyperthermia during infancy. F Appl Physiol 1992;73:32939

15 Gilbert R, Rudd P, Berry PJ, et al. Combined effect of infection and heavy wrapping on the risk of sudden unexpected infant death. Arch Dis Child 1992;67:171-7.

16 Trounce JQ, Lowe J, Lloyd BW, Johnston DI. Haemorrhagic shock encephalopathy and sudden infant death. Lancet 1991;337:202-3

17 Anderson ES, Wailoo MP, Petersen SA. Use of thermographic imaging to study babies sleeping at home. Arch Dis Child 1990;65:1266-7.

18 Jardine DS, Haschke RH. An animal model of lifethreatening hyperthermia during infancy. I Appl Physiol 1992;73:340-5.

19 Galland BC, Peebles CM, Bolton DPG, Taylor BJ. The micro-environment of the sleeping newborn piglet covered by bedclothes: gas exchange and temperature. 7 Paediatr Child Health 1994;30:144-50.

20 Foundation for the Study of Infant Deaths and Department of Health. Reduce the risk of cot death. London: Department of Health, 1996. 